www.nature.com/pj

\title{
Transparent ionic liquid-phenol resin hybrids with high ionic conductivity
}

\author{
Tomoki Ogoshi $^{1}$, Takeshi Onodera ${ }^{1}$, Tada-aki Yamagishi ${ }^{1}$, Yoshiaki Nakamoto ${ }^{1}$, Akihito Kagata ${ }^{2}$, \\ Noriyoshi Matsumi ${ }^{2}$ and Keigo Aoi $^{2}$
}

We report transparent ion conductive ionic liquid-phenol resin hybrids prepared by in situ polymerization/crosslinking of phenol monomer in ionic liquid. As ionic liquid, we used highly ion conductive ionic liquid 1-ethyl-3-methylimidazolium bis(trifluoromethanesulfonyl)amide ([EMI][TFSA]). Simultaneous polymerization and crosslinking of phenol with paraformaldehyde in [EMI][TFSA] yielded a highly transparent film. From a field emission scanning electron microscope (FE-SEM) image at 5000 magnification, the transparent hybrid prepared by in situ method did not show phase separation at 5000 magnification. In addition, from the FE-SEM image of the transparent hybrid at high magnification $(\times 60000)$, phenol resin and [EMI][TFSA] were observed to be integrated at a scale of a few nanometers. The transparent hybrid containing $20 \mathrm{wt} \%$ phenol resin showed high thermal stability and ionic conductivity $\left(1.0 \times 10^{-3} \mathrm{~S} \mathrm{~cm}^{-1}\right.$ at $\left.30^{\circ} \mathrm{C}\right)$, which is comparable to the pristine ionic liquid [EMI][TFSA]. Polymer Journal (2011) 43, 421-424; doi:10.1038/pj.2011.1; published online 16 February 2011

Keywords: hybrid materials; ionic conductivity; ionic liquids; phenol resin; solid polymer electrolyte

\section{INTRODUCTION}

Solid-state organic polymer electrolytes with high ionic conductivity have been the subject of extensive research for applications in electrical devices, such as fuel cells, lithium-ion rechargeable batteries and electric double-layer capacitors. ${ }^{1}$ Among them, solid-state organic polymer electrolytes hybridized with ionic liquids as electrolytes have recently attracted tremendous interest because ionic liquids show high ionic conductivity, low volatility, fire retardancy, noncorrosive nature, excellent solubility for both organic and inorganic compounds and high thermal stability. ${ }^{2}$ By mixing organic polymer and ionic liquids, solid-state ionic liquid-organic polymer hybrids have been prepared. ${ }^{3-14}$ However, in case of poor compatibility between organic polymer and ionic liquid, aggregation of organic polymer in ionic liquid occurred, and then ionic liquid leaked from the organic polymer matrix and the obtained composite material appeared turbid or phase separated. For preparation of homogeneous solid-state ionic liquid-organic polymer hybrids, improvement of compatibility is necessary. To improve compatibility, one attempt is utilizing covalent bonds between organic polymer and ionic liquid phases. By using vinyl monomers having ionic liquid moieties, organic polymers carrying ionic liquid moieties at the side chain were prepared. ${ }^{6-8}$ Organic polymers involving ionic liquid moieties in the main chain were also synthesized. ${ }^{9-12}$ The other approach for synthesis of the ionic liquid-organic polymer hybrids is the use of physical interactions between organic polymer and ionic liquid interfaces.
By using organic polymers that form physical interactions with ionic liquids, homogeneous ionic liquid-organic polymer hybrids were successfully obtained just by mixing ionic liquids and organic polymers. ${ }^{13,14}$ Therefore, investigation of physical interactions between organic polymers and ionic liquids is essential for the synthesis of homogeneous ionic liquid-organic polymer hybrid materials.

In this paper, we report ionic liquid-phenol resin hybrids prepared using the physical interaction between phenol polymer and ionic liquid. Recently, we studied polymerization of phenol in ionic liquids. ${ }^{15}$ During the research, it was found that phenol polymer formed a physical interaction with ionic liquids. From ${ }^{1} \mathrm{H}$ nuclear magnetic resonance measurements, the charge-transfer interaction from electron-donating phenol moieties to electron-accepting imidazolium cations was confirmed. Thus, by using the physical interaction between phenol polymer and ionic liquid, we synthesized ionic liquidphenol resin hybrids. As phenol polymer easily forms a thermally and mechanically stable three-dimensional network structure by curing, we prepared ionic liquid-phenol resin hybrids by curing phenol polymer with paraformaldehyde in ionic liquid. However, the surface of the obtained composite was very rough and heterogeneous (Figure 1a).

Because of the shrinking of phenol polymer during crosslinking reaction, aggregation of phenol resin should occur. Consequently, we synthesized ionic liquid-phenol resin hybrids by in situ method, which comprises initial polymerization of phenol and simultaneous

${ }^{1}$ Graduate School of Natural Science and Technology, Kanazawa University, Kakuma-machi, Kanazawa, Ishikawa, Japan and ${ }^{2}$ Graduate School of Bioagricultural Sciences, Nagoya University, Nagoya, Aichi, Japan

Correspondence: Dr T Ogoshi, Graduate School of Natural Science and Technology, Kanazawa University, Kakuma-machi, Kanazawa, Ishikawa 920-1192, Japan. E-mail: ogoshi@t.kanazawa-u.ac.jp

Received 23 September 2010; revised and accepted 27 December 2010; published online 16 February 2011 
crosslinking between phenol polymer chains in ionic liquid (Figure 1b). By using the in situ method, we successfully synthesized homogeneous and transparent ionic liquid-phenol resin hybrids. In this study, we revealed homogeneity, ion conductivity and thermal property of the transparent hybrids.

\section{EXPERIMENTAL PROCEDURE}

\section{Measurements}

${ }^{1} \mathrm{H}$ nuclear magnetic resonance spectra were recorded at 270 and $400 \mathrm{MHz}$ and ${ }^{13} \mathrm{C}$ nuclear magnetic resonance spectra were recorded at 67.5 and $100 \mathrm{MHz}$, with JEOL-JNM EX270 and EL400 spectrometers (JEOL, Tokyo, Japan), respectively. Field emission scanning electron microscopy (FE-SEM) measurements were recorded using a Hitachi S-4500 SEM apparatus (Hitachi, Tokyo, Japan). Thermogravimetric analysis was carried out using TG/DTA6200, SEIKO Instruments (Chiba, Japan), with a heating rate of $10^{\circ} \mathrm{Cmin}^{-1}$ under nitrogen atmosphere. Ionic conductivity was measured with a complex-impedance gainphase analyzer (Solartron model 1260; Schlumberger, Farnborough, UK) in the frequency range of 1-1 MHz. The samples were thoroughly dried under vacuum at $60^{\circ} \mathrm{C}$ for $24 \mathrm{~h}$ before recording measurements. The samples were sandwiched in a cell constructed with a pair of stainless steel plates. Gel permeation chromatography (GPC) analysis was carried out on Shodex (Tokyo, Japan) GPC LF804 by using tetrahydrofuran as an eluent at $25^{\circ} \mathrm{C}$ at the flow rate of $1 \mathrm{ml} \mathrm{min}^{-1}$ after calibration with the standard polystyrene samples.

1-Ethyl-3-methylimidazolium bis(trifluoromethanesulfonyl)amide([EMI][TFSA]) was synthesized according to previous literature. ${ }^{16}$

\section{Synthesis of phenol polymer}

To prepare ionic liquid-phenol resin hybrids by curing phenol polymer, we presynthesized the phenol polymer. To 2-ethoxyethanol $(3.75 \mathrm{ml})$, phenol $(0.47 \mathrm{~g}, 5.00 \mathrm{mmol})$ and paraformaldehyde $(0.16 \mathrm{~g}, 5.00 \mathrm{mmol})$ were added at room temperature. Further, catalytic sulfuric acid $(0.20 \mathrm{ml})$ was slowly added to the solution at $0{ }^{\circ} \mathrm{C}$. The mixture was stirred and then heated at $100^{\circ} \mathrm{C}$ for $3 \mathrm{~h}$. The

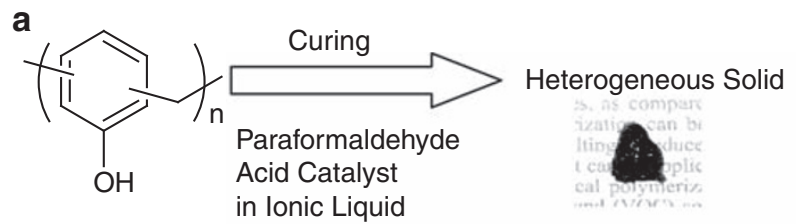

b<smiles>Oc1ccccc1</smiles>

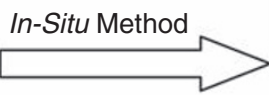

Paraformaldehyde Acid Catalyst in Ionic Liquid

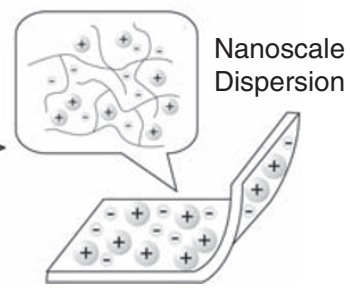

Ionic Liquid-Phenol Resin Hybrids

Figure 1 lonic liquid-phenol resin hybrids prepared by (a) curing phenol polymer and (b) in situ polymerization/crosslinking of phenol in ionic liquid. A full color version of this figure is available at Polymer Journal online. solution was poured into water. The solid was collected by filtration. Yield: $61 \%$; GPC analysis: $M_{\mathrm{w}}=18000, M_{\mathrm{w}} / M_{\mathrm{n}}=10.7$.

\section{Synthesis of ionic liquid-phenol resin hybrids by curing phenol} polymer in [EMI][TFSA]

To [EMI][TFSA] solution, presynthesized phenol polymer $(1.28 \mathrm{~g})$, paraformaldehyde $(0.10 \mathrm{~g})$ and para-toluenesulfonic acid $(13.9 \mathrm{mg})$ were added. The reaction mixture was heated at $80^{\circ} \mathrm{C}$ for $0.5 \mathrm{~h}$ for crosslinking reaction to proceed, after which the solution was placed in a container covered with a paper towel and left in an oven at $100^{\circ} \mathrm{C}$ for $3 \mathrm{~h}$. Finally, the mixture was heated under reduced pressure at $70{ }^{\circ} \mathrm{C}$ for $8 \mathrm{~h}$.

\section{Synthesis of ionic liquid-phenol resin hybrids by in situ method} Ionic liquid-phenol resin hybrids were prepared by in situ method (Table 1). To a solution of [EMI][TFSA], phenol and paraformaldehyde and para-toluenesulfonic acidwere added. The reaction mixture was heated at $80{ }^{\circ} \mathrm{C}$ for $0.5 \mathrm{~h}$ for polymerization to proceed, after which the solution was placed in a container covered with a paper towel and left in an oven at $100^{\circ} \mathrm{C}$ for $3 \mathrm{~h}$. Finally, the mixture was heated under reduced pressure at $70{ }^{\circ} \mathrm{C}$ for $8 \mathrm{~h}$.

\section{RESULTS AND DISCUSSION}

Ionic liquid-phenol resin hybrids were prepared by in situ method, which comprises initial polymerization of phenol and simultaneous crosslinking between phenol polymer chains in ionic liquid. To obtain highly ion-conductive ionic liquid-phenol resin hybrids, high ionconducting ionic liquid of [EMI] [TFSA] $\left(8.4 \times 10^{-3} \mathrm{~S} \mathrm{~cm}^{-1}\right.$ at $\left.30^{\circ} \mathrm{C}\right)$ was used in this work. Phenol and paraformaldehyde monomers were dissolved in [EMI][TFSA] and acid catalyst was added for the polymerization/crosslinking reaction. The reaction mixture was heated at $80{ }^{\circ} \mathrm{C}$ for polymerization to proceed, after which the solution was additionally heated in an oven at $100^{\circ} \mathrm{C}$. When aqueous sulfuric acid was used as an acid catalyst, the resulting solution was not solidified, indicating that polymerization of phenol did not proceed. Because of hydrophobicity of [EMI][TFSA], the catalyst of aqueous sulfuric acid was not homogeneously mixed with [EMI][TFSA] and thus polymerization of phenol hardly occurred. The trend was also observed in polymerization of phenol in hydrophobic ionic liquid of 1-hexyl-3methylimidazolium hexafluorophosphate. ${ }^{15}$ To overcome the problem we used organic acids. This is because organic acids are dissolved in hydrophobic [EMI][TFSA]. In case of oxalic acid used as an acid catalyst, the reaction mixture was homogeneous but the resulting solution was not solidified. By using para-toluenesulfonic acid, the reaction mixture containing more than $20 \mathrm{wt} \%$ monomer concentration changed to a solid film (Table 1, runs 1 and 2). The observation indicates that para-toluenesulfonic acid is a useful catalytic acid for the polymerization/crosslinking reaction of phenol in [EMI][TFSA] to proceed. Acidity of para-toluenesulfonic acid is stronger than that of oxalic acid; thus, the simultaneous polymerization/crosslinking reactions of phenol in [EMI][TFSA] should take place.

The obtained film was completely transparent (run 2, Figure 2b, inset) and showed no phase separation at 5000 magnification (run 2, Figure $2 \mathrm{~b}$ ). Figure $2 \mathrm{c}$ shows the FE-SEM image of the transparent hybrid film at high magnification $(\times 60000)$. Phenol resin, observed as

Table 1 Synthesis of ionic liquid-phenol resin hybrids

\begin{tabular}{lccccc}
\hline & PEMI][TFSA & Phenol & Paraformaldehyde & Monomer concentration & Para-toluenesulfonic acid \\
Run & $(g)$ & $(g)$ & $(g)$ & (wt\%) & Appearance \\
\hline 1 & 5.0 & 0.99 & 0.26 & 20 & 0.14 \\
2 & 5.0 & 1.61 & 0.54 & 30 & Transparent film \\
\hline
\end{tabular}

Abbreviation: [EMI][TFSA], 1-ethyl-3-methylimidazolium bis(trifluoromethanesulfonyl)amide. 
a

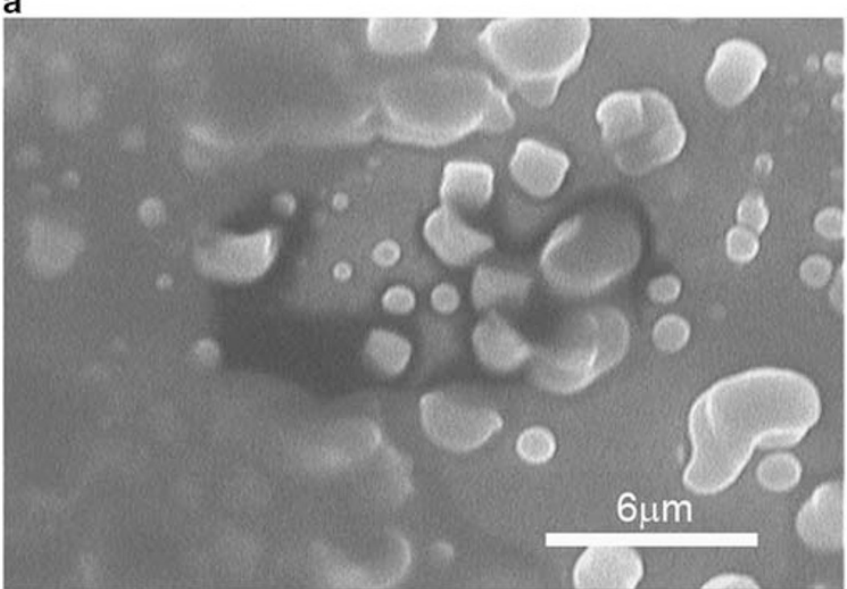

b

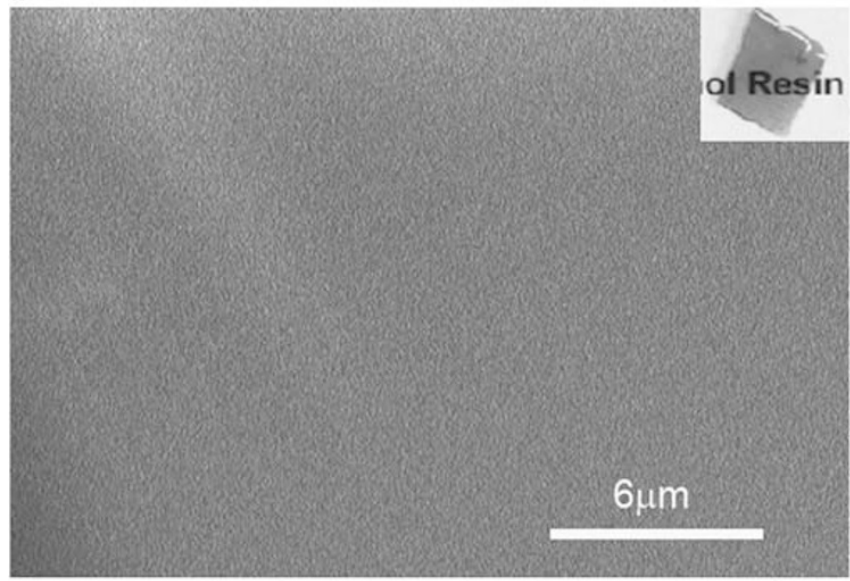

C

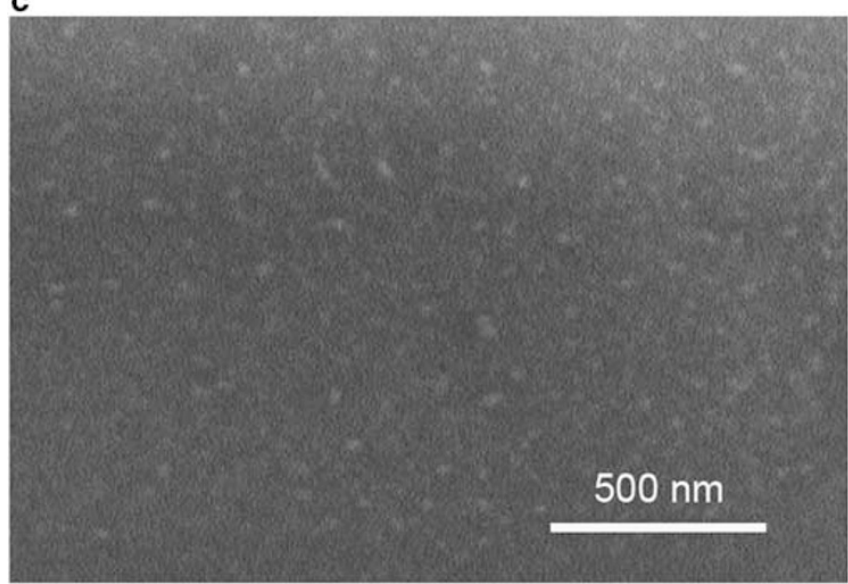

Figure 2 Field emission scanning electron microscope (FE-SEM) images of ionic liquid-phenol resin hybrids prepared by (a) curing phenol polymer $(\times 5000$, scale bar: $6 \mu \mathrm{m})$ and (b) in situ polymerization/crosslinking (run 2, $\times 5000$, scale bar: $6 \mu \mathrm{m}$ ) in 1-ethyl-3-methylimidazolium bis(trifluoromethanesulfonyl)amide (inset: photo of the transparent hybrid). (c) FE-SEM image of the sample in $\mathbf{b}$ at 60000 magnification (scale bar: $500 \mathrm{~nm}$ ). A full color version of this figure is available at Polymer Journal online.

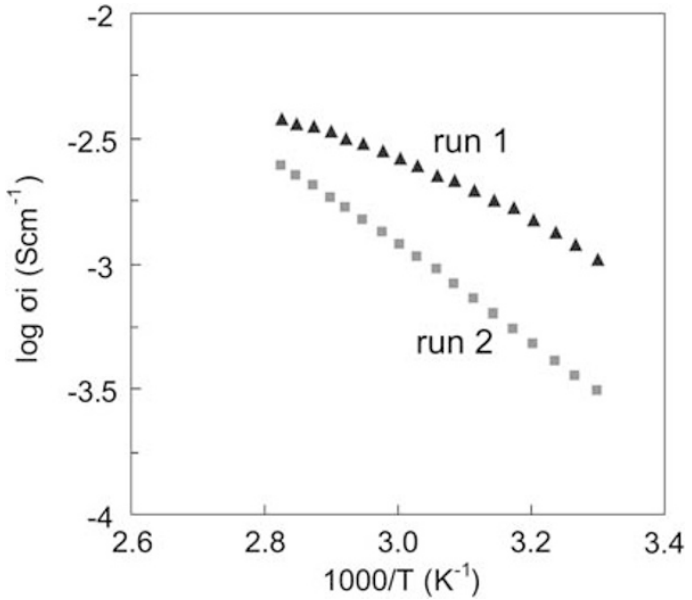

Figure 3 Temperature dependence of ion conductivity of the ionic liquidphenol resin hybrids from $20 \mathrm{wt} \%$ monomer (run 1, triangle) and $30 \mathrm{wt} \%$ monomer concentrations (run 2, square). A full color version of this figure is available at Polymer Journal online.

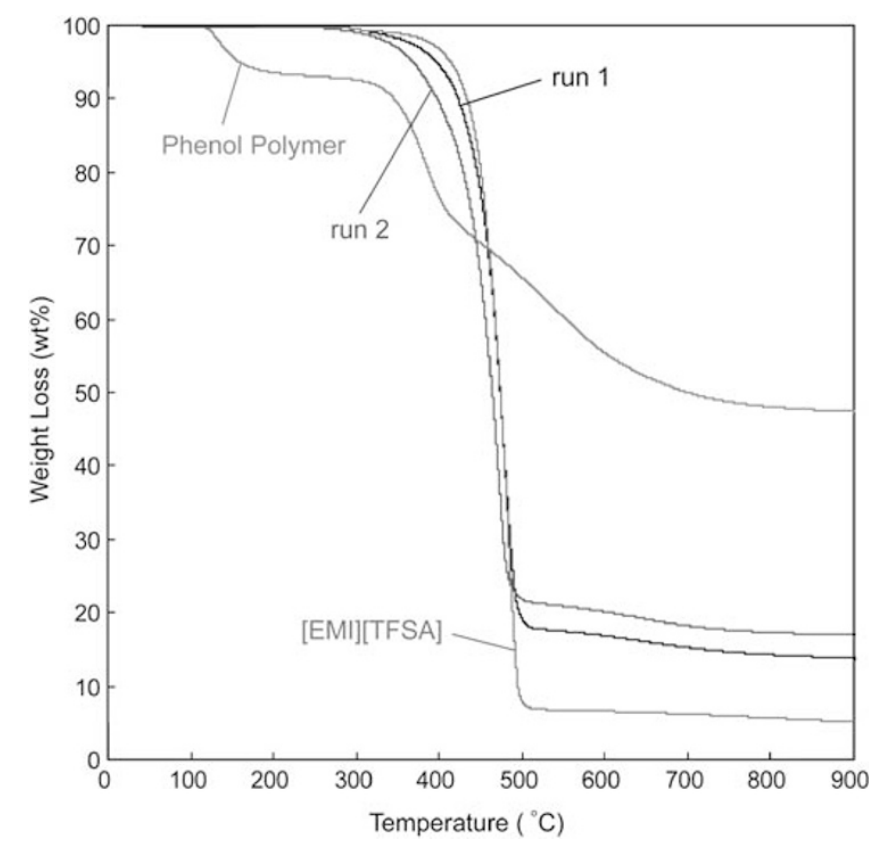

Figure 4 Thermogravimetric analysis study of the hybrid from $20 \mathrm{wt} \%$ monomer concentration (black line, run 1), from $30 \mathrm{wt} \%$ monomer concentration (blue line, run 2), 1-ethyl-3-methylimidazolium bis(trifluoromethanesulfonyl)amide ([EMI][TFSA]; green line) and phenol polymer (pink line) under nitrogen atmosphere. A full color version of this figure is available at Polymer Journal online.

bright spots, and [EMI][TFSA], observed as dark spots, were found to be dispersed uniformly at a level of a few nanometers in the sample. The result indicates nanometer-scale homogeneous distribution of each phase in the hybrid. Because of the dispersion of nanometer-sized components, the hybrid film avoided scattering loss, ${ }^{17}$ and thus showed high transparency. The obtained hybrid films were very soft and flexible, whereas phenol resin films are generally rigid and brittle.

Figure 3 shows temperature dependence of ionic conductivity for the hybrids prepared by in situ procedure. The hybrid prepared from $20 \mathrm{wt} \%$ monomer concentration (run 1) showed higher ionic conductivity in comparison with that from $30 \mathrm{wt} \%$ monomer concentration (run 2). 
Ionic conductivity for the hybrid film (run 1) was found to be $1.0 \times 10^{-3} \mathrm{~S} \mathrm{~cm}^{-1}$ at $30^{\circ} \mathrm{C}$, which was quite high for solid-state electrolytes comparable to pristine [EMI][TFSA] $\left(8.4 \times 10^{-3} \mathrm{~S} \mathrm{~cm}^{-1}\right.$ at $\left.30^{\circ} \mathrm{C}\right)$.

The thermal property of the transparent ionic liquid-phenol resin hybrid films prepared by in situ polymerization was examined by thermogravimetric analysis study (Figure 4). From thermogravimetric analysis measurement of the hybrid (run 1, monomer concentration: $20 \mathrm{wt} \%$ ), no mass loss was observed below $300^{\circ} \mathrm{C}$ and the $10 \mathrm{wt} \%$ loss temperature $\left(T_{10}\right)$ was found at $422^{\circ} \mathrm{C}$ (black line). In case of run 2 (monomer concentration: $30 \mathrm{wt} \%$ ), $T_{10}$ was observed at $397^{\circ} \mathrm{C}$ (blue line). [EMI][TFSA] (green line) showed high thermal stability ( $T_{10}$ was observed at $433{ }^{\circ} \mathrm{C}$ ). In contrast, thermal stability of the phenol polymer $\left(M_{\mathrm{w}}=18000, M_{\mathrm{w}} / M_{\mathrm{n}}=10.7\right)$ was not so high (pink line, $T_{10}$ was $346^{\circ} \mathrm{C}$ ). These observations indicate that thermal stability of the hybrids was improved as the content of [EMI][TFSA] increased.

\section{CONCLUSIONS}

We successfully synthesized transparent ionic liquid-phenol resin hybrids by in situ method. In the hybrids containing up to $20 \mathrm{wt} \%$ monomer concentration, the hybrids formed transparent and homogeneous self-supported film. Phenol resin and ionic liquid were uniformly dispersed at a level of a few nanometers. Ionic conductivity of the transparent hybrid film from the $20 \mathrm{wt} \%$ monomer concentration was $1.0 \times 10^{-3} \mathrm{~S} \mathrm{~cm}^{-1}$ at $30^{\circ} \mathrm{C}$, which is comparable to that of pristine [EMI][TFSA]. To the best of our knowledge, little is known about transparent ionic liquid hybrid materials with engineering plastics, whereas ionic liquid hybrids with typical polymers, such as poly(methyl methacrylate) and poly(ethylene oxide-co-propylene oxide), have been reported. ${ }^{13,14}$ Because phenol resin exhibits excellent thermal and mechanical properties, the ionic liquid-phenol resin hybrids will be applied for highly ion conductive film under severe conditions. We are now studying the mechanical and thermal stabilities of the hybrids.

\section{ACKNOWLEDGEMENTS}

This work was supported by Yazaki Memorial Foundation for Science and Technology and a Grant-in-Aid (KIBAN C-20550120 and WAKATE
B-21750140) from the Ministry of Education, Culture, Sports, Science and Technology, Japan.

1 Welton, T. Room-temperature ionic liquids. Solvents for synthesis and catalysis. Chem. Rev. 99, 2071-2084 (1999).

2 Martins, M. A. P., Frizzo, C. P., Moreira, D. N., Zanatta, N. \& Bonacorso, H. G. Ionic liquids in heterocyclic synthesis. Chem. Rev. 108, 2015-2050 (2008).

3 Matsumoto, K. \& Endo, T. Confinement of ionic liquid by networked polymers based on multifunctional epoxy resins. Macromolecules 41, 6981-6986 (2008).

4 Ueno, K., Sano, Y., Inaba, A., Kondoh, M. \& Watanabe, M. Soft glassy colloidal arrays in an ionic liquid: colloidal glass transition, ionic transport, and structural color in relation to microstructure. J. Phys. Chem. B 114, 13095-13103 (2010).

5 Gayet, F., Viau, L., Leroux, F., Mabille, F., Monge, S., Robin, J. J. \& Vioux, A. Unique combination of mechanical strength, thermal stability, and high ion conduction in PMMAsilica nanocomposites containing high loadings of ionic liquid. Chem. Mater. 21, 5575-5577 (2009).

6 Ohno, H. \& Ito, K. Room-temperature molten salt polymers as a matrix for fast ion conduction. Chem. Lett. 27, 751-752 (1998).

7 Yonezawa, M. \& Ohno, H. Molecular brush having molten salt domain for fast ion conduction. Chem. Lett. 28, 889-890 (1999).

8 Chen, H., Choi, J. H., de la Cruz, D. S., Winey, K. I. \& Elabd, Y. A. polymerized ionic liquids: the effect of random copolymer composition on ion conduction. Macromolecules 42, 4809-4816 (2009).

9 Matsumi, N., Sugai, K., Sakamoto, K., Mizuno, T. \& Ohno, H. Selective ion transport in organoboron polymer electrolytes bearing a mesitylboron unit. Macromolecules 35, 5731-5733 (2002).

10 Matsumi, N., Nakashiba, M., Mizuno, T. \& Ohno, H. Novel polymer/salt hybrid composed of comblike organoboron polymer electrolyte and boron-stabilized imido anion. Macromolecules 38, 2040-2042 (2005).

11 Matsumi, N., Sugai, K., Sakamoto, K., Mizuno, T. \& Ohno, H. Direct synthesis of poly(lithium organoborate)s and their ion conductive properties. Macromolecules $\mathbf{3 8}$, 4951-4954 (2005).

12 Matsumi, N., Sugai, K., Miyake, M. \& Ohno, H. Polymerized ionic liquids via hydroboration polymerization as single ion conductive polymer electrolytes. Macromolecules 39, 6924-6927 (2006).

13 Susan, M.A.B.H., , Kaneko, T., Noda, A. \& Watanabe, M. Ion gels prepared by in situ radical polymerization of vinyl monomers in an ionic liquid and their characterization as polymer electrolytes. J. Am. Chem. Soc. 127, 4976-4983 (2005).

14 Seki, S., Susan, M.A.B.H., Kaneko, T., Tokuda, H., Noda, A. \& Watanabe, M Distinct difference in ionic transport behavior in polymer electrolytes depending on the matrix polymers and incorporated salts. J. Phys. Chem. B 109, 3886-3892 (2005).

15 Ogoshi, T., Onodera, T., Yamagishi, T. \& Nakamoto, Y. Green polymerization of phenol in ionic liquids. Macromolecules 41, 8533-8536 (2008).

16 Bonhôte, P., Dias, A. P., Papageorgiou, N., Kalyanasundaram, K. \& Grätzel, M. hydrophobic, highly conductive ambient-temperature molten salts. Inorg. Chem. 35, 1168-1178 (1996).

17 Bohren, C F \& Huffman, D. R. eds Absorption and Scattering of Light by Small Particles (Wiley, New York, 1983). 